\title{
PERBANDINGAN PERFORMA ALGORITMA KOLONI SEMUT DENGAN ALGORITMA GENETIKA - TABU SEARCH DALAM PENJADWALAN KULIAH
}

\author{
Neng Ika Kurniati ${ }^{1}$, Alam Rahmatulloh ${ }^{2}$, Dewi Rahmawati ${ }^{3}$ \\ ${ }^{123}$ Program Studi Teknik Informatika, Univeristas Siliwangi, Tasikmalaya \\ Jalan Siliwangi No. 24 Tasikmalaya Jawa Barat, 46115 Indonesia
}

nengikakurniati@unsil.ac.id

\begin{abstract}
Abstrak - Algoritma digunakan sebagai penyelesaian beberapa masalah optimasi seperti traveling salesman problem maupun penjadwalan. Salah satu jenis algoritma yang sering digunakan adalah algoritma metaheuristik dimana algoritma ini menggunakan mekanisme yang meniru perilaku sosial ataupun strategi yang ada di alam. Algoritma koloni semut merupakan salah satu contoh algoritma metaheuristik yang memiliki cara kerja memilih jalur berdasarkan jalur yang paling sering dilalui oleh semut. Sedangkan salah satu contoh lain adalah algoritma genetika - tabu search yang memiliki cara kerja berkebalikan dimana algoritma ini mencegah agar jalur yang sama tidak dilakukan proses berulang ulang. Aktivitas penjadwalan kuliah dipilih untuk menjadi objek penelitian karena masalah penyusunan penjadwalan sangat kompleks, terdapat beberapa komponen yang harus dijadwalkan seperti dosen, mata kuliah, waktu, ruangan, dan kelas dengan memperhatikan sejumlah batasan dan syarat tertentu. Untuk itu dilakukan perbandingan kedua algoritma untuk mengetahaui algoritma mana yang lebih optimal dalam melakukan penyusunan penjadwalan kuliah. Hasil dari penelitian ini berupa. Hasil perbandingan menunjukan bahwa algoritma koloni semut lebih baik $33 \%$ dalam hal penggunaan memori dan lebih cepat $82 \%$ dalam pengukuran waktu, sedangkan algoritma genetika - tabu search lebih baik $11 \%$ dalam hal nilai fitness.
\end{abstract}

Keywords - Algoritma, Genetika - Tabu Search, Koloni Semut, Penjadwalan

\section{PENDAhuluan}

Penyusunan jadwal kuliah merupakan aktifitas penting yang membutuhkan waktu, tenaga dan ketelitian [1]. Karena dalam perancangan jadwal kuliah harus memperhatikan aturan aturan penjadwalan serta faktor faktor yang mempengaruhi seperti dosen, kelas, waktu, ruang dan mata kuliah dengan memperhatikan batasan dan syarat tertentu dalam mengalokasikan jadwal [2]. Beberapa solusi terhadap penyelesaian penjadwalan menunjukan bahwa semakin besar volume batasan penjadwalan maka alokasi akan jadwal semakin kompleks sehingga diperlukan algoritma untuk menyelesaikan permasalahan tersebut [1].

Metaheuristik merupakan algoritma yang dapat menyelesaikan masalah optimasi kompleks jika diselesaikan dengan algoritma eksak [3]. Algoritma metaheuristik memiliki kecepatan pencarian solusi optimal yang lebih baik daripada metode tradisional [4]. Menurut Hillier \& Lieberman metode metaheuristik yang dibangun dengan baik dapat memberikan solusi yang mendekati solusi optimal [5]. Metode metaheuristik berbasis AI (Artificial Intelligence) bermunculan untuk memberikan solusi yang optimal, seperti misalnya algoritma genetika, tabu search, koloni semut dan simulasi annealing [7]. Dalam penelitian yang dilakukan Rusidah, Muslim, \& Pramono penggabungan teknik algoritma genetika dengan tabu search menghasilkan optimasi lebih baik dibanding dengan teknik algoritma genetika saja [6]. Penelitian yang dilakukan oleh Komang Ayu Triana yang membandingkan algoritma koloni semut dengan algoritma tabu search menghasilkan bahwa algoritma tabu search menghasilkan proses yang cepat dan nilai pelanggaran kecil dibandingkan algoritma koloni semut [2]. Namun sesuai dengan studi pustaka yang dilakukan, saat ini penelitian Algoritma Koloni Semut dengan Algoritma Genetika - Tabu Search dilakukan pengimplementasian secara terpisah. Dimana Algoritma Koloni Semut merupakan algoritma yang menentukan jalur optimasi berdasarkan jalur yang paling sering dilalui. Sedangkan Algoritma Genetika-Tabu Search merupakan gabungan dari Algoritma Genetika dengan Algoritma Tabu Search yang cara kerjanya jalur yang pernah dilalui/dieksekusi tidak akan dieksekusi kembali, yang berarti cara kerjanya berkebalikan dengan Algoritma Koloni Semut.

Pada penelitian ini akan dilakukan perbandingan antara algoritma koloni semut dengan algoritma genetika-tabu search yang merupakan algoritma evolusi untuk menyelesaikan sebuah permasalahan penjadwalan mata pelajaran. Tujuan dari penelitian ini adalah untuk mengetahui hasil perbandingan performansi yang lebih baik antara algoritma koloni semut dan algoritma genetika-tabu search dalam menyelesaikan jadwal kuliah pada solusi terbaik.

\section{STUDI LITERATURE}

\section{A. Algoritma koloni semut (AKS)}

Dorigo[8] mendefinisikan bahwa algoritma ant colony optimization atau algoritma koloni semut (AKS) adalah algoritma yang awalnya terinspirasi dari perilaku semut, banyak dikembangkan bahwa spesies semut sangat peka terhadap suara, dan kebanyakan dari spesies mereka benar- 
benar buta, kebanyakan spesies semut hanya berkomunikasi antara individu dan individu, atau antara individu dan lingkungannya, spesies semut dapat menghasilkan sebuah cairan kimia yang disebut pheromone, dimana dengan cairan pheromone semut dapat meninggalkan jejak agar jejak tersebut dapat diikuti oleh semut lainnya seperti saat proses pencarian makanan oleh semut.

Pada ant colony optimization, sebuah koloni semut buatan bekerjasama untuk menemukan solusi terbaik terhadap sebuah permasalahan optimasi. Semut buatan mempunyai dua sifat (1) mencontoh dari sifat semut yang sesungguhnya yakni menemukan jalan tersingkat oleh koloni semut sungguhan, (2) memperkaya sebuah kemampuan yang tidak terdapat pada semut sungguhan [9].

\section{B. Algoritma genetika-tabu search (AG-TS)}

Algoritma genetika direpresentasikan oleh urutan langkah-langkah prosedur kromosom buatan yang bergerak dari satu populasi ke populasi baru menggunakan seleksi alami dan teknik yang diambil dari genetika yang dikenal sebagai crossover dan mutasi [10].

Menurut Glover dan Laguna kata tabu atau "taboo" berasal dari bahasa Tongan, suatu bahasa Polinesia yang digunakan oleh suku Aborigin pulau Tonga untuk mengindikasikan suatu hal yang tidak boleh "disentuh" karena kesakralannya. Menurut kamus Webster, tabu berarti larangan yang dipaksakan oleh kebudayaan sosial sebagai suatu tindakan pencegahan atau sesuatu yang dilarang karena berbahaya. Bahaya yang harus dihindari dalam Tabu Search adalah rute perjalanan yang tidak layak, dan terjebak tanpa ada jalan keluar [11]. Pada metode tabu search, solusi yang sudah pernah ditemui akan dilarang untuk di eksekusi kembali pada iterasi berikutnya. TS menggunakan struktur memory yang disebut Tabu List. Tabu List digunakan untuk menyimpan solusi yang pernah ditemui selama iterasi berjalan agar proses pencarian tidak berulang-ulang pada daerah solusi yang sama, selain itu untuk menuntun proses pencarian menelusuri solusi-solusi yang belum pernah dikunjungi sebelumnya [6].

\section{Penjadwalan}

Penjadwalan adalah penempatan sumber daya (resource) dalam satu waktu. Penjadwalan mata kuliah merupakan persoalan penjadwalan yang umum dan sulit dimana tujuannya adalah menjadwalkan pertemuan dari sumber daya. Sumber daya yang dimaksud adalah dosen pengasuh mata kuliah, mata kuliah, ruang kuliah, kelas mahasiswa, dan waktu. [12].

\section{Constraint}

Terdapat batasan-batasan (constraints) dalam penyusunan penjadwalan mata kuliah. Batasan-batasan yang tidak boleh dilanggar dalam penjadwalan adalah sebagai berikut:

1. Tidak boleh ada jadwal diruang yang sama di waktu yang sama atau bisa disebut Clash Ruangan (CR).

2. Tidak boleh ada jadwal untuk kelas yang sama di waktu yang sama atau bisa disebut Clash Class (CC).
3. Tidak boleh ada jadwal untuk dosen yang sama mengajar di waktu yang sama atau bisa disebut Clash Dosen (CD).

4. Tidak boleh ada jadwal untuk dosen dihari yang telah ditentukan oleh dosen atau bisa disebut Clash $\operatorname{Hari}(\mathrm{CH})$.

\section{Fitness}

Nilai fitness digunakan untuk proses evaluasi node dan kromosom agar memperoleh node dan kromosom yang diinginkan. Fungsi ini membedakan kualitas dari node dan kromosom untuk mengetahui seberapa baik node dan kromosom yang dihasilkan. Fungsi fitness tersebut sesuai dengan persamaan 1 .

$$
\text { Fitness }=\frac{1}{1+\text { penalty }}
$$

Dari persamaan diatas nilai fitness ditentukan oleh nilai penalty. Penalty tersebut menunjukkan jumlah pelanggaran kendala pada suatu kromosom. Semakin tinggi nilai fitness akan semakin besar kemungkinan node dan kromosom tersebut terpilih ke generasi berikutnya. Jadi nilai penalty berbanding terbalik dengan nilai fitness, semakin kecil nilai penalty (jumlah pelanggaran) semakin besar nilai fitnessnya.

Didalam penjadwalan perkuliahan ini penalty menunjukkan besarnya nilai pelanggaran (Constraint). Bobot nilai pelanggaran terhadap $\mathrm{CR}, \mathrm{CD}, \mathrm{CC}$ adalah 1 dan pelanggaran terhadap $\mathrm{CH}$ adalah 0,5. Maka model perhitungannya dapat dilihat pada persamaan 2 .

$$
\text { Fitness }=\frac{1}{1+C C+C D+C R+C H}
$$

\section{METODOLOGI PENELITIAN}

Metode yang digunakan adalah metode studi komparatif dimana setiap algoritma diuji dari segi kinerja algoritma. Kemudian hasil dari pengujian dibandingkan menggunakan parameter penggunaan memori, parameter waktu, dan parameter nilai fitness. Tahap - tahap yang digunakan yaitu :

1. Pengumpulan data

2. Persiapan data

3. Persiapan pengujian

4. Mengukur penggunaan memori

5. Mengukur waktu

6. Menghitung nilai fitness

7. Membandingkan hasil pengukuran

8. Penarikan kesimpulan

\section{A. Pengumpulan data}

1. Algoritma koloni semut (AKS)

Algoritma koloni semut memiliki cara kerja memilih jalur terbaik berdasarkan jumlah feromon (jejak kaki), semakin sering node dilalui semut maka feromon akan semakin kuat. Semut pertama akan mencari node pada kolom pertama secara acak untuk jadwal mata kuliah pertama. Jika node yang didapat sesuai dengan ketentuan misalnya dosen mata kuliah tidak sedang mengajar pada timeslot di node tersebut atau ruangan tersedia maka node tersebut akan diupdate feromonnya. Namun jika node yang 
didapat tidak sesuai dengan ketentuan misalnya ruangan sedang digunakan pada node tersebut maka semut akan mencari node lain lagi secara acak yang masih dikolom tersebut sampai mendapat node yang sesuai ketentuan.

Setelah mendapat node pada kolom pertama, semut akan mencari node pada kolom kedua dan seterusnya sampai

Page | 19 kolom terakhir. Setelah mendapat node pada kolom terakhir, semut lain akan mencari jalur seperti yang dilakukan semut pertama.

Setelah beberapa semut memiliki jalur, semjut berikutnya dapat memilih untuk mencari jalur sendiri atau mengikuti jalur semut yang sudah mendapat nilai feromon paling kuat. Jalur yang paling banyak digunakan oleh semut yang akan dijadikan pertimbangan untuk jalur optimal.

\section{Algoritma genetika - tabu search $(A G-T S)$}

Cara kerja algoritma ini ada memilih kromosom terbaik berdasarkan seleksi crossover dan mutasi. Langkah pertama dari algoritma ini adalah membentuk populasi awal, lalu tiap kromosom dalam populasi tersebut akan diubah menjadi nilai integer. Selanjutnya kromosom kromosom akan mengalami penyeleksian dengan menggunakan tabu search. Dalam tabu search ini, solusi yang sudah pernah ditemui akan dilarang untuk di eksekusi kembali pada iterasi berikutnya. TS menggunakan struktur memory yang disebut tabu list. tabu list digunakan untuk menyimpan solusi yang pernah ditemui selama iterasi berjalan agar proses pencarian tidak berulang-ulang pada daerah solusi yang sama, selain itu untuk menuntun proses pencarian menelusuri solusisolusi yang belum pernah dikunjungi sebelumnya. Setelah terbentuk kromosom kromosom baru, kromosom tersebut akan menlalui proses crossover gen tiap kromosom. Hasil dari crossover tersebut lalu dilakukan kembali mutasi gen. Sehingga terbentuklah populasi baru dengan kromosom yang baru.

\section{B. Persiapam data}

Jumlah data yang digunakan dalam penelitian ini dijelaskan pada tabel 1 .

TABEL I

PERSIAPANDATA

\begin{tabular}{|c|l|l|}
\hline NO & JENIS DATA & JUMLAH \\
\hline 1 & Data ruangan & 11 data \\
\hline 2 & Data dosen & 20 data \\
\hline 3 & Data Waktu & 51 data \\
\hline 4 & Data Kuliah & 70 data \\
\hline
\end{tabular}

\section{Persiapan pengujian}

Tahap persiapan dilakukan dengan mendefinisikan kebutuhan perangkat yang digunakan. Kebutuhan perangkat dalam penelitian ini dibagi menjadi 3, yaitu kebutuhan perangkat keras, kebutuhan perangkat lunak dan kebutuhan komponen pengujian.

\section{Kebutuhan perangkat keras}

Beberapa perangkat keras yang dibutuhkan dalam penelitian ini, berikut dijelaskan pada Tabel 2.
TABELII

KEBUTUHAN PERANGKAT KERAS

\begin{tabular}{|c|l|l|}
\hline NO & NAMA & JUMLAH \\
\hline 1 & $\begin{array}{l}\text { Laptop Asus AMD A9-9420 } \\
\text { Ram 3GB }\end{array}$ & Unit \\
\hline
\end{tabular}

2. Kebutuhan perangkat lunak

Beberapa perangkat lunak yang dibutuhkan untuk penelitian ini, berikut dijelaskan pada Tabel 3.

TABEL III

KEBUTUHAN PERANGKAT LUNAK

\begin{tabular}{|c|l|l|}
\hline NO & \multicolumn{1}{|c|}{ NAMA } & \multicolumn{1}{|c|}{ FUNGSI } \\
\hline 1 & Windows 10 Pro & Sistem Operasi \\
\hline 2 & Google Chrome & $\begin{array}{l}\text { Browser web } \\
\text { menjalankan } \\
\text { aplikasi }\end{array}$ \\
\hline 3 & Web Server & $\begin{array}{l}\text { Untuk menjalankan } \\
\text { sever (localhost) }\end{array}$ \\
\hline 4 & Database & $\begin{array}{l}\text { Untuk menyimpan data } \\
\text { aplikasi }\end{array}$ \\
\hline 5 & PHP & $\begin{array}{l}\text { Bahasa pemrograman } \\
\text { yang digunakan }\end{array}$ \\
\hline 6 & $\begin{array}{l}\text { Adobe } \\
\text { Dreamweaver CC } \\
2018\end{array}$ & $\begin{array}{l}\text { Untuk merancang web } \\
\text { aplikasi yang } \\
\text { digunakan dalam } \\
\text { perhitungan kinerja }\end{array}$ \\
\hline
\end{tabular}

\section{Kebutuhan komponen pengujian}

Beberapa komponen data yang digunakan untuk penelitian ini, berikut dijelaskan pada Tabel 4

TABELIV

KEBUTUHAN KOMPONEN PENGUJIAN

\begin{tabular}{|c|l|l|}
\hline NO & \multicolumn{1}{|c|}{ NAMA } & \multicolumn{1}{|c|}{ ENTITAS } \\
\hline 1 & Data dosen & $\begin{array}{l}\text { Kode dosen, nama } \\
\text { dosen, hari dosen } \\
\text { mengajar }\end{array}$ \\
\hline 2 & Data mata kuliah & $\begin{array}{l}\text { Kode mata kuliah, } \\
\text { nama mata kuliah }\end{array}$ \\
\hline 3 & Data waktu & Nama hari. Nama jam \\
\hline 4 & Data ruangan & $\begin{array}{l}\text { Kode ruangan, Nama } \\
\text { ruangan }\end{array}$ \\
\hline
\end{tabular}

\section{Mengukur penggunaan memori}

Pengukuran penggunaan data dilakukan dengan menggunakan fungsi php. Yaitu fungsi untuk melakukan pengukuran jumlah memori yang digunakan oleh sistem dalam kilo bytes. Kode sumber tertera pada Gbr 1

echo "Ir|nMemory Usage: " , memory_get_usage() / 1024 , ' kilo bytes';

Gbr 1. Kode sumber untuk mengukur penggunaan memori 


\section{E. Mengukur waktu}

Dalam melakukan pengukuran waktu dilakukan dengan cara pendefinisian variabel time_start sebelum eksekusi kode metode kemudian definisikan time_end setelah selesai eksekusi kode metode kemudian lakukan pengurangan (pencarian selisih). Dapat dilihat dari Gbr 2.

Page | 20

\begin{tabular}{|c|c|c|}
\hline 6 & 8696.11 & 17539.03 \\
\hline 7 & 8756.97 & 16506.14 \\
\hline 8 & 8718.17 & 16417.1 \\
\hline 9 & 7000.41 & 15307.28 \\
\hline 10 & 7055.89 & 15323.62 \\
\hline Rata - rata & 8544.44 & 17010.28 \\
\hline
\end{tabular}

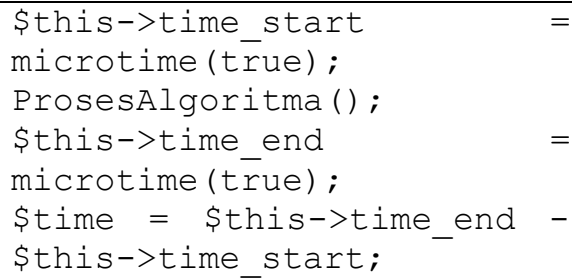

Gbr 2. Kode sumber untuk mengukur waktu

F. Menghitung nilai fitness

Perhitungan nilai fitness disesuaikan dengan persamaan 2. Kode sumber untuk perhitungan nilai fitness tertera pada Gbr 3.

\$f['nilai'] = $1 /(1+$
\$clash_dosen +
\$clash_ruang +
\$Clash_kelas +
\$Clash_hari);

Gbr3. Kode sumber untuk nilai fitness

G. Membandingkan hasil pengukuran

Hasil - hasil pengukuran dari pengujian dihimpun dan diambil nilai rata - rata setiap parameter. Kemudian dibandingkan data tersebut antar algoritma yang digunakan.

\section{H. Penarikan kesimpulan}

Menganalisis data pengujian antara kedua algoritma yang digunaka kemudian menentukan metode mana yang lebih baik dari segi masing masing parameter. Sehingga dapat diketahui algoritma mana yang unggul.

\section{IV.HASIL DAN ANALISIS}

A. Hasil pengukuran penggunaan memori

Hasil pengukuran memori terhadap penjadwalan dengan algoritma koloni semut dan algoritma genetika - tabu search. Dengan hasil algoritma koloni semut rata - rata menggunakan memori sebesar 8544.44 kilo bytes, sedangkan algoritma genetika - tabu search rata - rata menggunakan memori sebesar 17010.28 kilo bytes. Data hasil pengukuran penggunaan memori disajikan pada tabel 5, Gbr 4 dan Gbr 5.

TABEL V

HASIL PENGGUNAAN MEMORI

\begin{tabular}{|c|c|c|}
\hline \multicolumn{3}{|c|}{ Hasil Pengukuran Memori (kilo bytes) } \\
\hline Percobaan Ke - & AKS & AG - TS \\
\hline 1 & 9540.37 & 18247.17 \\
\hline 2 & 9106.8 & 17965.03 \\
\hline 3 & 8720.75 & 17965.03 \\
\hline 4 & 8678.85 & 17366.89 \\
\hline 5 & 9170.14 & 17465.46 \\
\hline
\end{tabular}

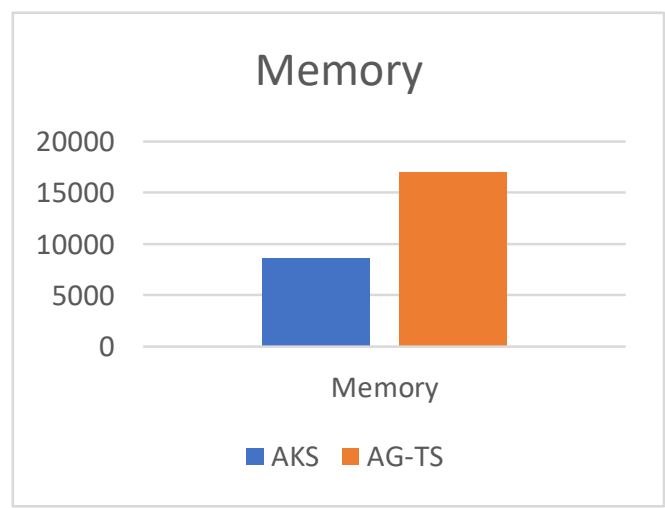

Gbr 4. Hasil pengukuran memori

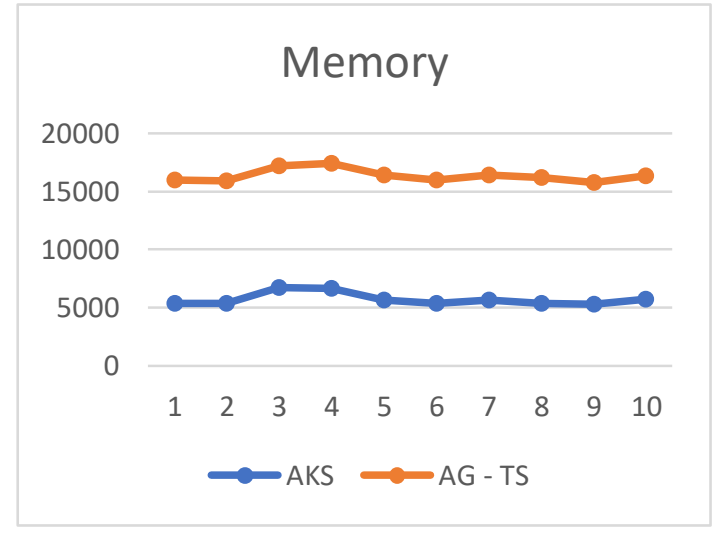

Gbr 5. Perubahan penggunaan memori tiap percobaan

B. Hasil pengukuran penggunaan waktu

Hasil pengukuran waktu terhadap penjadwalan dengan algoritma koloni semut dan algoritma genetika - tabu search. Dengan hasil algoritma koloni semut rata - rata menggunakan waktu sebanyak 12.22 detik, sedangkan algoritma genetika - tabu search rata - rata membutuhkan waktu sebanyak 122.86 detik. Data hasil pengukuran penggunaan waktu disajikan pada tabel 6, Gbr 6 dan Gbr 7 .

TABEL VI

HASIL PENGUKURAN WAKTU

\begin{tabular}{|c|c|c|}
\hline \multicolumn{3}{|c|}{ Hasil Pengukuran Waktu (s) } \\
\hline $\begin{array}{c}\text { Percobaan Ke } \\
-\end{array}$ & AKS & AG - TS \\
\hline 1 & 14.85 & 136.17 \\
\hline 2 & 22.88 & 138.09 \\
\hline 3 & 10.73 & 138.09 \\
\hline 4 & 11.02 & 130.7 \\
\hline 5 & 10.52 & 127.26 \\
\hline 6 & 10.64 & 124.22 \\
\hline 7 & 10.75 & 116.21 \\
\hline
\end{tabular}




\begin{tabular}{|c|c|c|}
\hline 8 & 11.48 & 115.39 \\
\hline 9 & 9.97 & 96.35 \\
\hline 10 & 9.42 & 106.12 \\
\hline Rata - rata & 12.22 & 122.86 \\
\hline
\end{tabular}

Page $\mid 21$

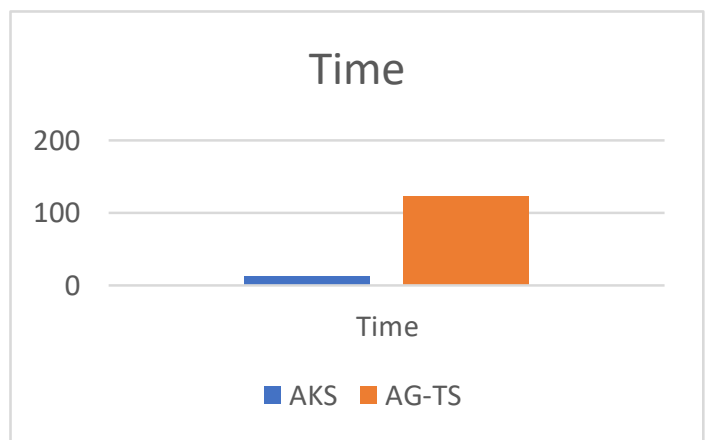

Gbr 6. Hasil pengukuran waktu

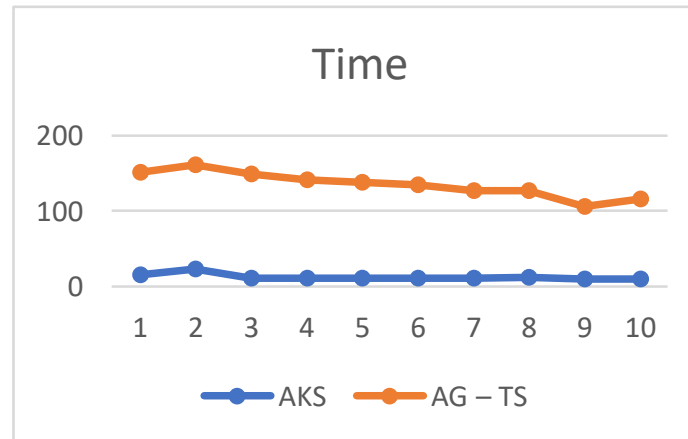

Gbr 7. Perubahan waktu tiap percobaan

\section{Hasil pengukuran nilai fitness}

Hasil pengukuran nilai fitness terhadap penjadwalan dengan algoritma koloni semut dan algoritma genetika tabu search. Dengan hasil algoritma koloni semut rata - rata menghasilkan nilai fitness 0.0135 dengan nilai CD 18.2, CR 25.4, CK 12,4 dan CH 18,05, sedangkan algoritma genetika - tabu search rata - rata menghasilkan nilai fitness 0.0171 dengan nilai CD 14.2, CR 17, CK 10.2, dan CH 16.15. Data hasil pengukuran penggunaan waktu disajikan pada tabel 7 , tabel 8, Gbr 8 dan Gbr 9.

TABEL VII

HASIL PENGUKURAN NILAI FITNET AKS

\begin{tabular}{|c|c|c|c|c|c|}
\hline $\begin{array}{c}\text { Percobaan } \\
\text { Ke - }\end{array}$ & Fitness & CD & CR & CK & CH \\
\hline 1 & 0.0138 & 28 & 14 & 12 & 17 \\
\hline 2 & 0.0173 & 10 & 18 & 10 & 18.5 \\
\hline 3 & 0.0106 & 24 & 40 & 8 & 21 \\
\hline 4 & 0.0099 & 20 & 44 & 14 & 22 \\
\hline 5 & 0.0134 & 26 & 18 & 12 & 17.5 \\
\hline 6 & 0.0152 & 12 & 20 & 16 & 16.5 \\
\hline 7 & 0.0143 & 22 & 22 & 8 & 16.5 \\
\hline 8 & 0.0139 & 12 & 30 & 14 & 14.5 \\
\hline 9 & 0.0136 & 12 & 26 & 16 & 18.5 \\
\hline 10 & 0.0139 & 16 & 22 & 14 & 18.5 \\
\hline Rata - rata & 0.0135 & 18.2 & 25.4 & 12.4 & 18.05 \\
\hline \multicolumn{5}{|c|}{ TABEL VIII } \\
\hline
\end{tabular}

HASSIL NILAIFITNES AG-TS

\begin{tabular}{|c|c|c|c|c|c|}
\hline \multicolumn{6}{|c|}{ Hasil Pengukuran nilai fitness AG-TS } \\
\hline $\begin{array}{c}\text { Percobaan } \\
\text { Ke - }\end{array}$ & Fitness & CD & CR & CK & CH \\
\hline 1 & 0.0176 & 22 & 12 & 6 & 15.5 \\
\hline 2 & 0.0156 & 20 & 18 & 10 & 15 \\
\hline 3 & 0.0191 & 12 & 14 & 6 & 19.5 \\
\hline 4 & 0.0165 & 12 & 18 & 16 & 13.5 \\
\hline 5 & 0.0169 & 14 & 14 & 14 & 16 \\
\hline 6 & 0.0155 & 18 & 18 & 12 & 15.5 \\
\hline 7 & 0.0178 & 8 & 20 & 12 & 15 \\
\hline 8 & 0.0175 & 10 & 16 & 12 & 18 \\
\hline 9 & 0.0181 & 10 & 26 & 2 & 16 \\
\hline 10 & 0.0165 & 16 & 14 & 12 & 17.5 \\
\hline Rata - rata & 0.0171 & 14.2 & 17 & 10.2 & 16.15 \\
\hline \multicolumn{7}{|c|}{}
\end{tabular}

\section{Fitness}

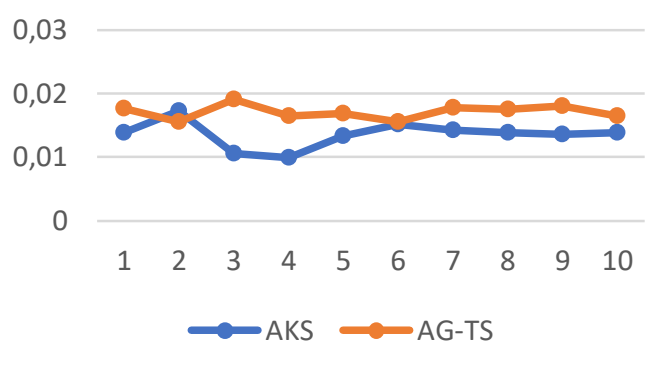

Gbr 8. Perubahana nilai fitness tiap percobaan

\section{Clash Dosen}

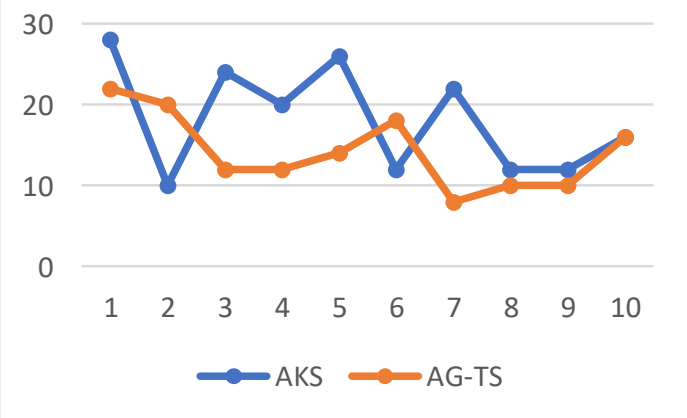

Gbr 9. Perubahan clash dosen tiap percobaan

\section{Clash Ruangan}

50

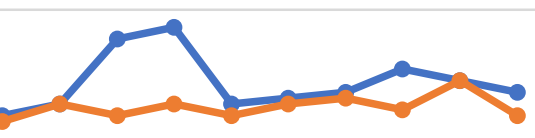

0

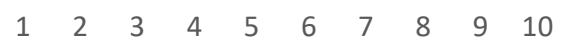

$\longrightarrow$ AKS $\longrightarrow$ AG-TS

Gbr 10. Perubahan clash ruangan tiap percobaan

\section{Clash Class}

20 
Gbr 11. Perubahan clash class tiap percobaan

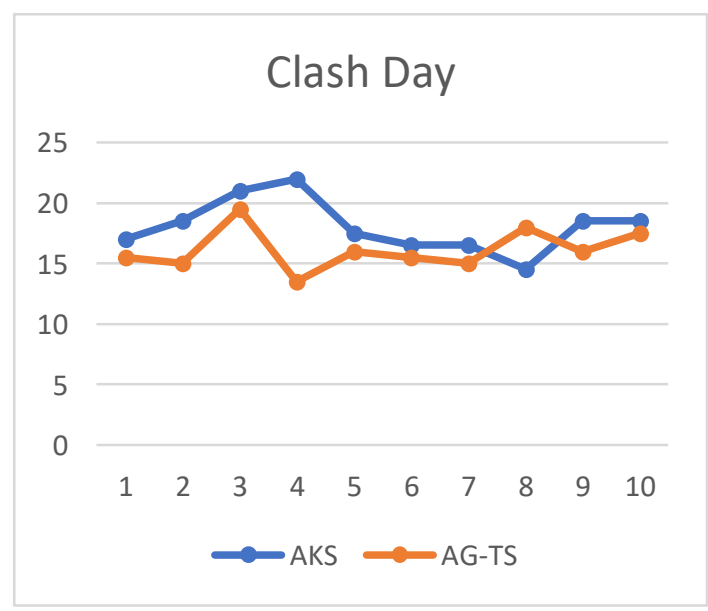

Gbr 12. Perubahan clash day tiap percobaan

Untuk mengukur keakuratan nilai fitness, maka dilakukan perhitungan manual nilai fitness dengan jumlah sampel 10 data untuk tiap tiap algoritma dengan hasil dapat dilihat pada tabel 9.

TABEL IX

HASIL SAMPLE NILAI FITNES

\begin{tabular}{|l|l|l|}
\hline NO & \multicolumn{1}{|c|}{ AKS } & AG-TS \\
\hline 1 & 0.2 & 0.5 \\
\hline
\end{tabular}

Hasil percobaan algoritma koloni semut terdapat pada Gbr 13

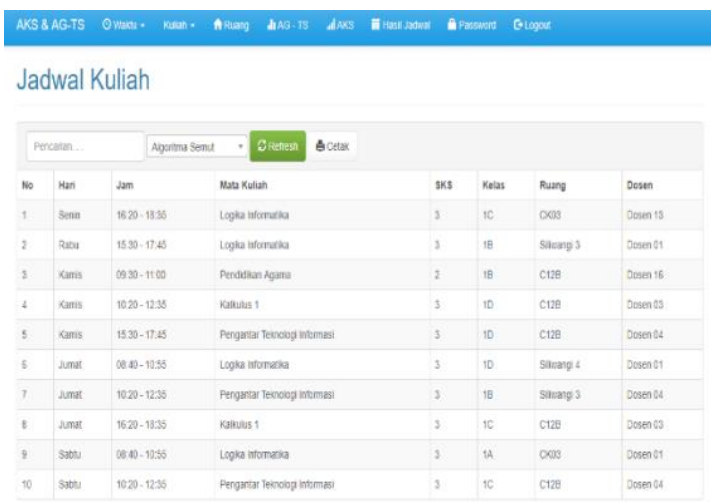

Gbr 13. Hasil jadwal algoritma koloni semut

Dengan batasan hari dosen terdapat pada Gbr 14.

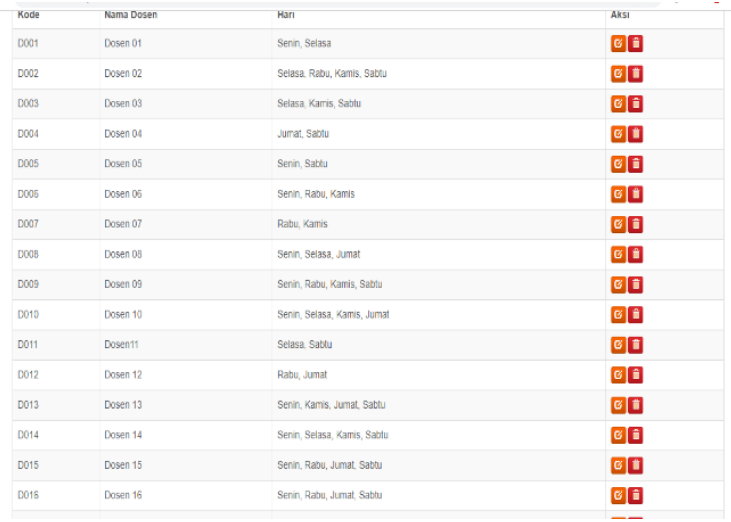

Gbr 14. Constraint

Dari hasil percobaan diatas terdapat pelanggaran batasan berupa kelas C12B pada hari Kamis dijadwalkan bersamaan, dosen 1 yang mengajar dihari Rabu, Kamis, Sabtu, dosen 16 yang mengajar pada hari Kamis, dosen 3 yang mengajar pada hari jumat, serta dosen4 yang mengajar pada hari Kamis. Maka hasil nilai fitness sesuai persamaan 2 menjadi Fitness $=$ $\frac{1}{1+0+0+1+3}=0.2$ dan nilai fitness untuk algoritma semut terbukti.

Hasil percobaan algoritma genetika - tabu search dapat dilihat pada Gbr 15

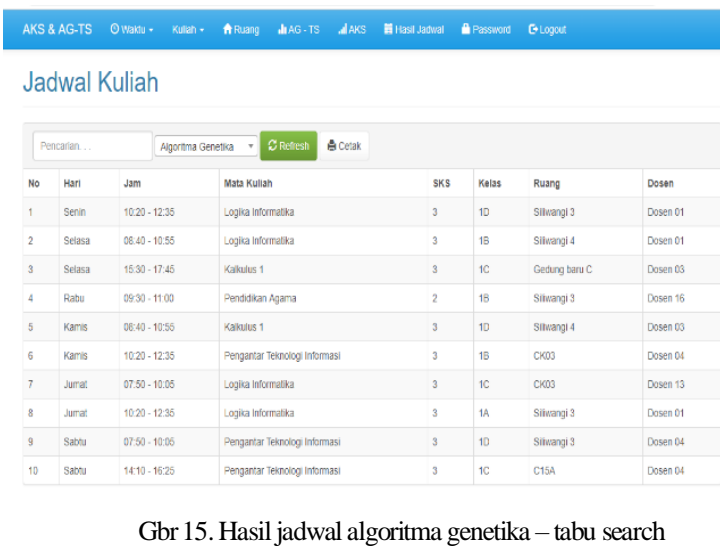

Dengan batasan hari untuk dosen dapat dilihat pada Gbr 14. Dari hasil percobaan diatas pelanggaran hanya terdapat pada batasan hari dosen pada dosen 1 yang mengajar pada hari jumat dan dosen 4 yang mengajar pada hari sabtu. Maka nilai fitness yang didapat sesuai dengan persamaan 2 adalah Fitness $=\frac{1}{1+0+0+0+1}=$ 0.5 dengan begitu nilai fitness untuk algoritma genetika - tabu search terbukti.

\section{Analisis}

Hasil Pengukuran penggunaan memori terhadap penjadwalan dengan menggunakan algoritma koloni semut dan algoritma genetika - tabu search. Dengan hasil algoritma koloni semut rata-rata menggunakan memory sebesar 8544.44 kilo bytes dan algoritma genetika - tabu search rata-rata menggunakan memori sebesar 17010.28 kilo bytes. 
Hasil pengukuran waktu terhadap penjadwalan dengan menggunakan algoritma koloni semut dan algoritma genetika - tabu search. Dengan hasil algoritma koloni semut rata-rata membutuhkan waktu 12.22 detik dan algoritma genetika - tabu search ratarata membutuhkan waktu 122.86 detik.

Hasil perhitungan nilai fitness terhadap penjadwalan dengan menggunakan algoritma koloni semut dan algoritma genetika - tabu search. Dengan hasil algoritma koloni semut rata-rata menghasilkan nilai fitness 0.0135 , dengan rata rata nilai CD 18.2, CR 25.4, CK 12.4 dan $\mathrm{CH} 18.05$ sedangkan algoritma genetika - tabu search rata-rata menghasilkan nilai fitness 0.0171 dengan rata rata nilai CD 14.2, CR 17, CK 10.2 dan CH 16.15. Hasil perbandingan algoritma bisa dilihat di tabel 10

TABEL X

KESIMPULAN

\begin{tabular}{|c|c|c|}
\hline $\begin{array}{c}\text { Algoxitma } \\
\text { Parameter }\end{array}$ & AKS & AG - TS \\
\hline $\begin{array}{c}\text { Penggunaan } \\
\text { Memory }\end{array}$ & 8544.44 & 17010.28 \\
\hline Waktu & 12.22 & 122.86 \\
\hline Nilai Fitness & 0.0135 & 0.0171 \\
\hline CD & 18.2 & 14.2 \\
\hline CR & 25.4 & 17 \\
\hline CK & 12.4 & 10.2 \\
\hline CH & 18.05 & 16.15 \\
\hline
\end{tabular}

\section{KESIMPULAN}

Berdasarkan hasil analisis dari penelitian ini, maka kesimpulan yang diperoleh adalah sebagai berikut. Kinerja algoritma koloni semut dalam penjadwalan menggunakan memori $33 \%$ lebih sedikit dibanding algoritma genetika tabu search. Kinerja algoritma koloni semut menggunakan waktu $82 \%$ lebih cepat dalam menghasilkan penjadwalan. Nilai fitness algoritma genetika - tabu search lebih baik $11 \%$ dibandingkan dengan algoritma koloni semut.

Untuk penerapan kedalam penjadwalan disarankan menggunakan algoritma genetika - tabu search karna meskipun penggunaan memori tidak sehemat algoritma koloni semut dan penggunaan waktu tidak secepat algoritma koloni semut tapi algoritma genetika $11 \%$ lebih baik dinilai fitness dibandingkan algoritma koloni semut, yang artinya dalam penjadwalan algoritma genetika - tabu search jadwal yang bentrok lebih sedikit dibandingkan algoritma koloni semut.

Berdasrkan hasil penelitian yang telah dilakukan, ada beberapa kekurangan dari penelitian ini. Karena metode pengujian yang digunakan oleh penulis masih sederhana, maka penulis menyarankan untuk dilakukan pengujian kedua algoritma dengan metode yang lainnya. Dalam hasil penelitian ini, nilai fitness yang dihasilkan kurang dari satu yang artinya masih terdapat bentrok dalam penjadwalan. Maka penulis menyarankan untuk dilakukan penelitian pengoptimalan algoritma agar menghasilkan nilai fitness satu.

\section{UCAPAN TERIMAKASIH}

Penulis mengucapkan terima kasih kepada semua pihak yang telah membantu baik secara moril maupun materil terhadap penelitian ini.

\section{REFERENSI}

[1] D. R. Anamisa, "Implementasi Alokasi Jadwal Mata Pelajaran Smu Menggunakan Algoritma Koloni Semut," 2014

[2] K. A. T. Indah, "Komparasi Metode Ant Colony Optimazation dengan Tabu Search untuk Penjadwalan Perkuliahan," 2017.

[3] V. T. R, "Perbandingan Basic Variant pada Algoritma Particle Swarm Optimization," 2015.

[4] M. Madi, D. Markovi and M. Radovanovi, "Comparison of Meta-Heuristic Algorithms for Solvng Machining Optimization Problems," Mechanical Engineering, vol. 11, 2013.

[5] F. Hillier and G. Lieberman, Introduction to Operation Research, New York: McGraw-Hill, 2010.

[6] Rusianah, M. A. Muslim and S. H. Pramono, "Implementasi Algoritma Genetika-Tabu Search dalam Optimasi Penjadwalan Perkuliahan," 2016.

[7] S. Kusumadewi, Artificial Intelligence (Teknik dan Aplikasinya), Yogyakarta: Graha Ilmu, 2003.

[8] M. Dorigo, " Ant Algorithms Solve Difficult Optimization Problems," in In Advances in Artificial Life., Springer Berlin Heidelberg, 2001.

[9] M. Dorigo, M. Birattari and T. Stützle, "Ant Colony Optimization," 2006.. [Online].

[10] M. Negnevitsky, Artificial Intteligence-A Guide to Intelligent Systems, Edinburg: Addison Wesley, 2005.

[11] F. Glover and M. Laguna, Tabu Search, Boston: Kluwer, 1997.

[12] E. L. Mooney, LARGE SCALE CLASSROOM SCHEDULING, Montana State University: Industrial and Management Engineering Department, 1995. 